ARTICLE

https://doi.org/10.1057/s41599-019-0368-9

\title{
Voters' involvement, attitude, and confidence in the era of new media
}

Hang Lee (1) ${ }^{1 \star}$

\begin{abstract}
Social network sites have now become one of the important media channels for election campaigns. Researches in the domain of social sciences are starting to form a picture of how social network site itself might affect political participation. However, there has not been much attention given to the influence of the determinants of social network site usage on voters' involvement and their attitude and confidence. Thus, this research extends the concept of previous research and aims to examine the relationship between the determinants of social network site usage, voters' involvement with politics, voters' attitude toward voting, and their confidence of voting decision. This research uses a mediation regression model to run a Likert scaled dataset from 211 questionnaires. The results of this research show that the three determinants of social network site usage have positive impact on voters' involvement with politics, which further affects voters' attitude toward voting and their confidence of decisions. More specifically, social network site users' 'need to belong' and their 'perceived ease of use' towards the sites significantly increase their involvement with politics and further enhance their attitude toward voting and their confidence of voting decisions. This research has several contributions in the field of academic and management. First, it provides a framework to explain the impact of social network sites usage on voters' attitude and confidence. Second, it provides an empirical support for using actual data from actual social network site users. Third, the findings of this research indicate that when intending to strengthen voters' attitude toward voting in order to enhance voting rate or to raise voters' confidence of their voting decisions on a specific candidate or party, political campaign managers and candidates are suggested to take into account users' feel of belongings in a certain online community and their perceived effort when using a certain social network site.
\end{abstract}

\footnotetext{
${ }^{1}$ Graduate Institute of Business Administration, College of Management, National Taiwan University, Taipei 10617, Taiwan. *email: d04741008@ntu.edu.tw
} 


\section{Introduction and research background}

W ith the development of the Internet, the usage of social network sites has increased considerably. Social network sites have rapidly become one of the main media channels for all types of campaigns and have gradually become an alternative tool for marketing and service delivery (Chadwick, 2006; Davis, 2010; Gulati, 2004; Tsai and Men, 2017). During the 2008 United States presidential election, Barack Obama's election team used social network sites to effectively recruit thousands of volunteers (Dickinson, 2008). In the 2016 United States presidential election, Donald Trump widely used social network sites to create political issues during his election campaigns (Enli, 2017; Ott, 2017). Furthermore, political consulting firms, such as Cambridge Analytica, have been influencing voters' involvement, attitudes, and confidence through social network sites by using behavioural microtargeting techniques (Persily, 2017; Ward, 2018). This situation is also noted in countries other than the United States. For instance, V-Dem, a Sweden research institution, reported that among 72 countries worldwide, Taiwan has received the largest amount of false or misleading information on political topics; because Taiwanese people use online media and social network sites extensively, false and misleading information and the resulting online information fractionalisation are likely to affect Taiwan's political results (Lindberg et al., 2019).

The influence of social network sites on political involvement and attitude has received considerable attention from academic researchers and business managers over the past few years. Seidman (2013) used the concept of the 'need to belong'-first defined by Baumeister and Leary (1995) as 'people's need to be loved and socially accepted'-for conducting an online social research; the results indicated that the need to belong is a major motivator for using social network sites. People can fulfil their need to belong by using the features of social network sites; these include the ability to communicate, gather information, express opinions, obtain social approval, and influence others; by using these services. Flanagin and Metzger (2001) examined people's motivations for using numerous different media platforms and reported that the Internet was heavily used for social bonding and relationship maintenance. Moreover, Kwon and Wen (2010) used Davis's technology acceptance model (TAM) to evaluate social network site usage in their research and concluded that their model-including 'perceived ease of use' (i.e., degree to which a person believes that using a specific system would be effortless) and 'perceived usefulness' (i.e., extent to which a person believes that using a specific system would improve their performance)exhibited high predictive validity for social network site use.

According to previous studies, the perceived ease of use, perceived usefulness, and need to belong are strongly correlated with the usage of social network sites (Adams et al., 1992; Baumeister and Leary, 1995; Chang and Chuang, 2011; Williams and Cothrel, 2000). Research on involvement with political processes has long been conducted (Muehling et al., 1993; Pinkleton, 1998). Studies have indicated that 'involvement' refers to a psychological state of an individual and defines the importance and personal relevance of a certain component to a person (Hartwick and Barki, 1994; O'Cass and Fenech, 2003). According to this definition, we defined voters' involvement with politics as the importance and personal relevance of politics to voters. Voters' involvement with politics refers to the extent to which the voters view politics as the central part of and a meaningful and engaging object in their lives and indicates its importance for them. On the basis of previous results, this study further argues that when users seek belongingness and social acceptance on social network sites or when they feel using a social network site would be effortless and would improve their performance, their involvement with political issues strengthens.

In the literature on involvement, some researchers have indicated that involvement is positively associated with attitude based on the assertion that a person's attitude is influenced by their perceptions of relevance (Ajzen and Fishbein, 1977; Jackson et al., 1997). Barki and Hartwick (1994) defined 'attitude' as 'an individual's internal evaluation of an object or a topic'; the authors indicated that users who believe a certain issue to be crucial and personally relevant have come to influence their attitude. In addition, voters' confidence in their decisions may be influenced by their degree of political involvement. The relationship between involvement and confidence has been studied previously: O'Cass and Pecotich (2005) and Zechman (1979) both have indicated that voters with less involvement will have lower confidence level in their voting choices. Based on previous studies, this study defines voters' 'confidence' as 'extent to which voters believe in their ability to make the right choice and select a suitable party or candidate'.

The current study extended the aforementioned research concept and argues that the determinants of social network site usage in terms of need to belong, perceived ease of use, and perceived usefulness can eventually influence voters' attitude towards voting and their confidence in their decisions because voters may have a high degree of internal evaluation of the voting and perceived ability to select the suitable party or candidate by viewing politics as a crucial topic or central focus of their lives. In this study, we proposed that voters' involvement with politics mediates the relationship between social network site usage determinants (independent variables) and voters' attitude towards voting and voters' confidence in their decisions (dependent variables) and developed a conceptual model (Fig. 1) to answer two research questions: (1) Do the determinants of social network site usage influence users' involvement with politics? (2) What is the relationship between users' involvement with politics, attitude towards voting, and confidence in their voting decision in the context of social network sites? Moreover, we further developed five hypotheses:

H1: Social network site usage determinants positively influences voters' involvement with politics.

H2: Voters' involvement with politics is positively related to voters' voting attitude.

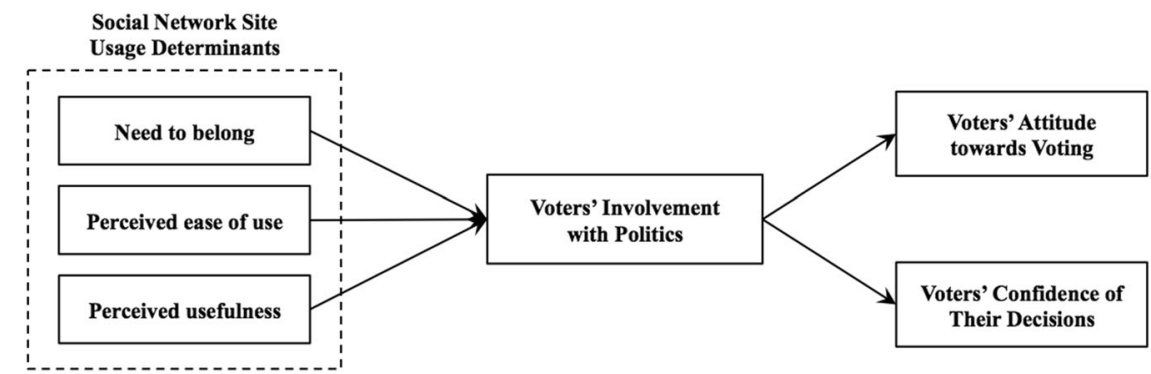

Fig. 1 The research model. 
H3: Voters' involvement with politics is positively related to voters' confidence in their decisions.

H4: Voters' involvement with politics mediates the effects of social network site usage determinants for their attitude towards voting.

H5: Voters' involvement with politics mediates the effect of social network site usage determinants on their confidence in their decisions.

\section{Research method}

Data collection and sample. We used a survey questionnaire to collect data for testing the validity of the research model and hypotheses. The variables in the questionnaire include background information, social network site usage determinants, voters' involvement with politics, voters' attitude towards voting, and voters' confidence in their decisions. The measurement items in the final questionnaire are summarised in Supplementary Appendix A. All the variables were measured on the Likert fivepoint scale ranging from strongly disagree (1) to strongly agree (5), except for background information. For the survey, we selected Facebook users of voting age in Taiwan as the survey population. We chose Taiwan as the research subject country because the study was conducted in Taiwan, Taiwan's democracy system has long been threatened by the neighbouring countries, and Taiwan has received the largest amount of false or misleading information on political topics from the Internet (Lindberg et al., 2019). We selected Facebook as the social network site to be explored because it exhibits the highest penetration (89\%) among all the social network sites in Taiwan, followed by Instagram (49\%) and Twitter (24\%). Facebook was used by nearly all social network site users across Taiwan, establishing it as the most popular social network site in Taiwan (Statista, 2019).

We collected data through an online survey platform. The links to the online questionnaires were distributed using Facebook to recruit respondents. All respondents were voluntarily participating in the research and informed about the use of data for academic research. The process yielded 400 responses. After eliminating the responses of respondents that failed to meet voting age (20 years old) or answer key questions and after sending follow-up emails to respondents who had provided their contact information but had not finished the questionnaire, we eventually obtained 211 valid questionnaires for the analysis.

Next, the possibility of non-response bias was assessed using an extrapolation method comparing late and early respondents (Armstrong and Overton, 1977). The results of the t-statistics indicated no differences across either substantive or demographic variables, suggesting the absence of nonresponse bias. The demographic characteristics of the sampled population are presented in Supplementary Appendix B. The distributions are similar to the overall demographic characteristics of Facebook users in Taiwan (female users: 55\%, male users: $45 \%$, the largest proportion of age range: 18-34 years old) (Facebook, 2019).

Measures. The aforementioned questionnaire was developed by reviewing literature to identify previously validated measurements, some of which were revised to adapt to the context of politics. Subsequently, Cronbach's alpha coefficient, which demonstrates the internal consistency and reliability of the measures, was calculated for each factor. Based on the suggestion of Hair et al. (1998), factors with an $\alpha$ of $<0.7$ were eliminated from the questionnaire.

Based on a study by Pinkleton et al. (2002), a four-item scale designed to reflect voters' attitudes toward voting $(\alpha=0.914)$ was included. In addition, on the basis of O'Cass's (2002) study, a three-item scale was included to measure the extent of voters' confidence in their ability to make the right decision and perceived ability to select the suitable party or candidate $(\alpha=0.947)$. Items for the need to belong were adopted from the study of Seidman (2013) to determine the extent to which users require belongingness by using a five-item scale $(\alpha=0.808)$. Five items for perceived ease of use and another five for perceived usefulness were adapted from the study of Kwon and Wen (2010), for which respondents indicated the extent of effort when using the social network site $(\alpha=0.898)$ and the extent to which the social network site was considered useful $(\alpha=0.915)$. Five items for voters' involvement with politics were adopted from the study by Kwon and Wen (2010) to determine the extent to which voters view politics as the central part of their lives and a meaningful and engaging object in their lives and its importance to them $(\alpha=0.934)$. Finally, single-item scales were adopted to measure the five control variables, namely age, gender, education, occupation, and monthly income because demographic differences may constitute the sociocultural factors that influence the perception and behaviour; therefore, these variables may influence voters' attitude towards politics and their confidence in decisions (Gefen and Straub, 1997).

Measurement model. The mean, standard deviation, and correlations of all measured variables are listed in Table 1. In addition to Crobach's alpha coefficients, this research used variance inflation factors (VIFs) to examine the effects of multicollinearity. VIFs indicate whether predictors are correlated to each other, which can affect $\mathrm{p}$ values in the model and reduce its reliability. According to Hair et al. (1998), VIF > 10 indicates a strong correlation. VIFs presented in Table 1 exhibit a range of 1.330-2.710, with a mean of 1.950 , indicating the absence of multicollinearity.

Structural model. To analyse the relationships among social network site usage determinants, voters' involvement with politics, their attitude towards voting, and their confidence in their decisions, regression models were run with related variables, and the result is presented in Table 2. Models 1a, 2a and 3a in Table 2 are the basis models including the five control variables. The results of aforementioned models indicated no significant influence on dependent variables except Model 2a $(F=0.828$, $R^{2}=0.020 ; F=3.139, R^{2}=0.071$ and $F=1.880, R^{2}=0.044$ for Models 1a, $2 \mathrm{a}$ and $3 \mathrm{a}$, respectively). Model $1 \mathrm{~b}$ was run to analyse the direct effects of social network site usage determinants on voters' involvement with politics. The model demonstrated significant results, explaining $44.7 \%\left(\Delta R^{2}=0.447\right)$ of variance over what the control variables alone explained. The coefficients of users' need to belong, perceived ease of use, and perceived usefulness were positive and significant for voters' involvement with politics $(\beta=0.342, p<0.001 ; \beta=0.324, p<0.001$ and $\beta=0.153$, $p<0.05$, respectively). Models $2 c$ and $3 c$ were run to test the direct effects of voters' involvement with politics on voters' attitude towards voting and voters' confidence in their decisions. Both models provided significant results. The coefficients of voters' involvement with politics were positive and significant for both voters' attitude towards voting $(\beta=0.675, p<0.001)$ and voters' confidence in decisions $(\beta=0.581, p<0.001)$. Figure 2 presents the results for structural model.

Mediating effect. To test the mediating effects of voters' involvement with politics, this study used a sequential procedure, reported by Baron and Kenny (1986). First, Models 2b and 3b were run to test the effects of the independent variables on the dependent variables. The coefficients of the need to belong $(\beta=0.264, p<0.001)$, perceived ease of use $(\beta=0.256, p<0.001)$, and perceived usefulness $(\beta=0.139, p<0.1)$ were positively and significantly related to voters' attitude towards voting. And The 


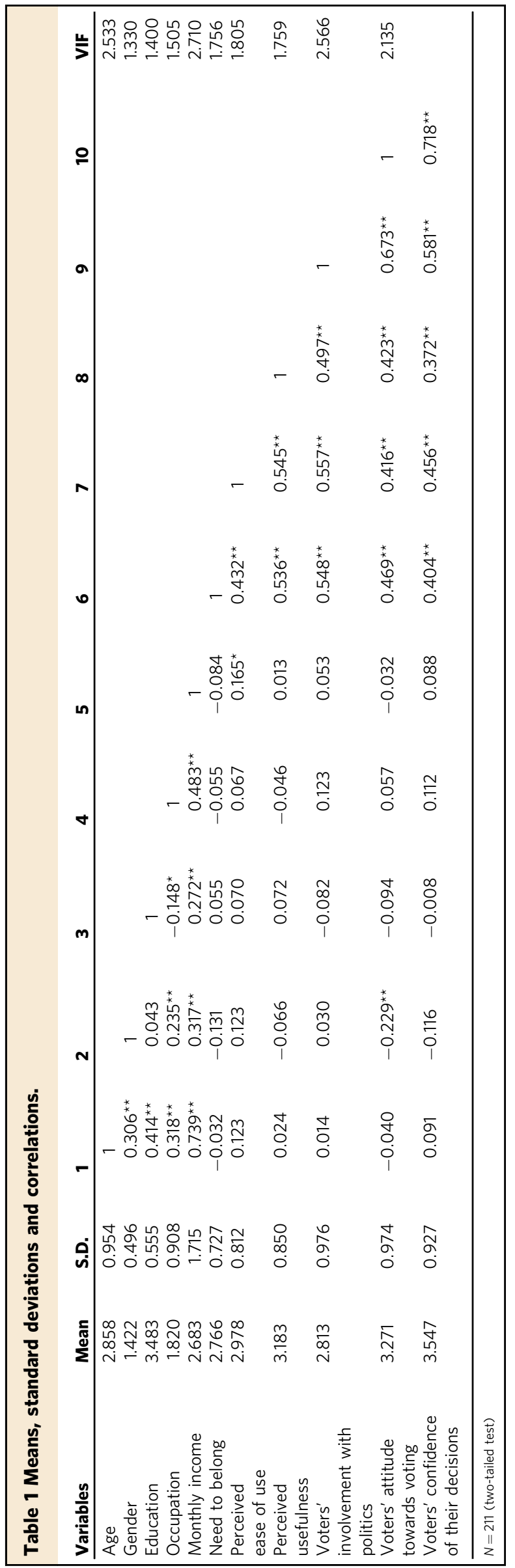

coefficients of the need to belong $(\beta=0.209, p<0.01)$ and perceived ease of use $(\beta=0.332, p<0.001)$ were positively and significantly related to voters' confidence in their decisions, thus fulfilling the first requirement for the mediating effect. Second, Model $1 \mathrm{~b}$ in Table 2 indicates that the relationship between voters' involvement with the politics and the need to belong, perceived ease of use, and perceived usefulness were also significant, meeting the second requirement for the mediating effect. Third, voters' involvement with politics was added as the mediator to examine the final requirement for the mediating effect (Model 2d and 3d). The direct effects of the need to belong $(\beta=0.069)$, perceived ease of use $(\beta=0.072)$, and perceived usefulness $(\beta=0.052)$ on voters' attitude towards voting became nonsignificant when voters' involvement with politics was added as a mediator, and the overall fit of the models improved $\left(\Delta R^{2}=0.172\right)$. Similarly, the significance level of the effects of the need to belong $(\beta=0.060)$, perceived ease of use $(\beta=0.191, p<$ $0.01)$, and perceived usefulness $(\beta=0.007)$ on voters' confidence in their decisions also decreased as the overall model fit improved $\left(\Delta R^{2}=0.101\right)$.

Finally, to examine mediating effects further, the Sobel test-a specialised $t$ test that can be used to determine the reduction in the independent variable in the model after including the mediator, was performed. As shown in Table 2, the need to belong $(\beta=5.03, p<0.001$ in Model 2 and $\beta=4.79, p<0.001$ in Model 3), perceived ease of use ( $\beta=4.69, p<0.01$ in Model 2 and $\beta=4.50, \quad p<0.001$ in Model 3 ), and perceived usefulness $(\beta=2.24, p<0.05$ in Model 2 and $\beta=2.22, p<0.05$ in Model 3 ) exhibited significant and indirect effects on voters' attitude towards voting and voters' confidence in their decisions, further supporting the mediating effect of voters' involvement with politics for influencing the effects of the need to belong, perceived ease of use, and perceived usefulness on voters' attitude towards voting and voters' confidence in their decisions.

\section{Results}

Based on the results of regression analysis (Table 2), the findings of Model $1 \mathrm{~b}$ indicated that voters highly involve with politics when they use social network sites. These findings are support $\mathrm{H} 1$ : social network site usage determinants positively influences voters' involvement with politics. The positive and significant coefficients from Model $2 \mathrm{c}$ and $3 c$ indicated that voters exhibit considerably positive attitude towards voting and high degrees of confidence on decisions when they achieve a high level of involvement with politics. These findings support $\mathrm{H} 2$ and $\mathrm{H} 3$ : voters' involvement with politics significantly influence their attitude towards voting and voters' confidence in their decisions.

According to the results from Models $1 b, 2 c$ and $3 c$ in Table 2, the need to belong, perceived ease of use, and perceived usefulness influence voters' involvement with politics, and voters' involvement with politics influences voters' attitude towards voting and voters' confidence in their decisions. These results confirm the first precondition of $\mathrm{H} 4$ and $\mathrm{H} 5$, which includes mediating effects. Next, when testing the effects of independent variables on dependent variables, we observed that three independent variables, namely the need to belong, perceived ease of use, and perceived usefulness directly influence dependent variables, namely voters' attitude towards voting and their confidence in their decisions. These results meet the second precondition of $\mathrm{H} 4$ and $\mathrm{H} 5$.

The results of Models $2 \mathrm{~d}$ and $3 \mathrm{~d}$ presented in Table 2 indicate that voters' involvement with politics successfully mediate the effects of the need to belong, perceived ease of use, and perceived usefulness on voters' attitude towards voting and voters' confidence in their decisions. These results support $\mathrm{H} 4$ and $\mathrm{H} 5$ and indicated that voters' involvement with politics mediates the 


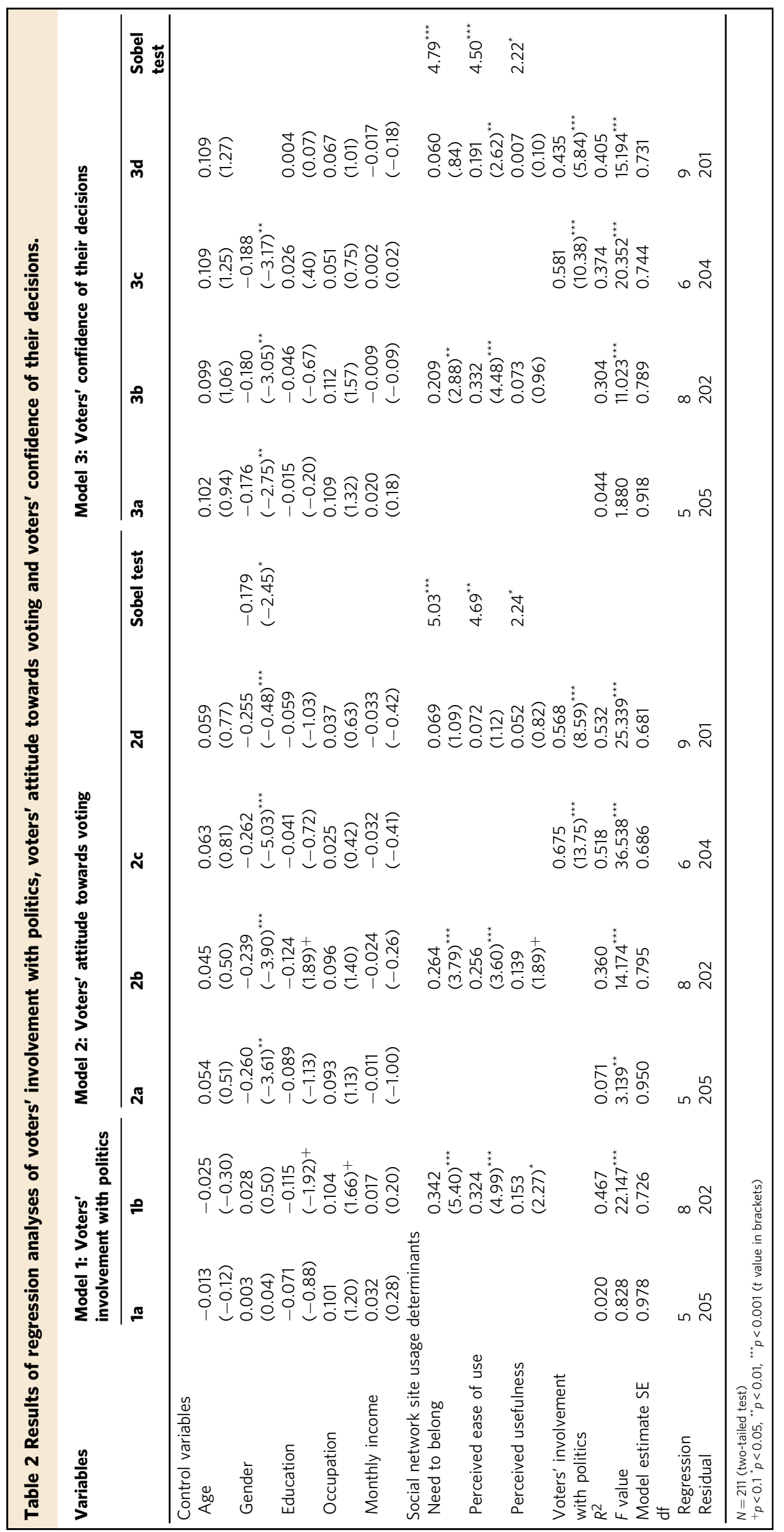




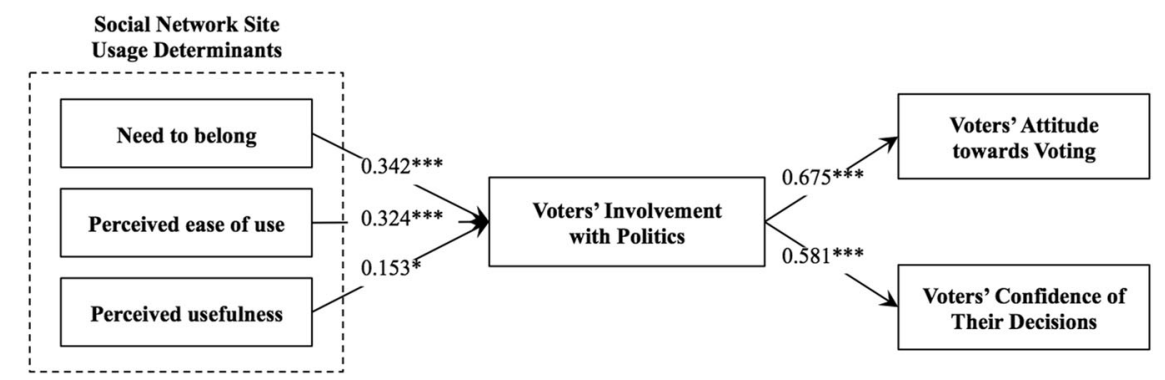

Fig. 2 Results from the structural model analysis.

effects of the three factors of social network usage determinants, namely the need to belong, perceived ease of use, and perceived usefulness on voters' attitude towards voting and voters' confidence in their decisions.

\section{Discussion}

This study presents a conceptual model for examining the relationships of social network site usage determinants with voters' involvement with politics, attitude towards voting, and confidence of their decisions. In this study, data collected from Taiwan, which holds direct elections and has high social network site penetration rate, were analysed; The results indicated that (1) users' need to belong, perceived ease of use, and perceived usefulness among social network sites directly and positively influences their involvement with politics (Model $1 \mathrm{~b}$ in Table 2); (2) their involvement with politics directly and positively influences their attitudes towards voting and confidence in decisions (Model $2 c$ and $3 c$ in Table 2); and (3) their involvement with politics mediates the effects of their need to belong, perceived ease of use, and perceived usefulness on their attitudes towards voting and confidence in their decisions (Model 2d and 3d in Table 2). These findings strongly support the argument that users' need to belong, perceived ease of use, and perceived usefulness for using social network sites facilitate their involvement with politics and further improve their attitude towards voting and confidence in their decisions and emphasises the critical role of social network sites in current political elections.

This study next discusses several theoretical and practical issues for both scholars and practitioners and presented many opportunities for further explorations. First, unlike past research on social media and politics that has focused on the user path and behaviour, the current empirical study ascertained social network site usage determinants that lead to voters' attitude and confidence and the mediating factors of involvement, all in the context of politics, because of the recent emphasis on the impact of social media on elections by providing a conceptual framework (Fig. 1) and using data obtained from actual social network site users.

Second, by using the TAM and need to belong theory, this research iterates the crucial factors of social network site usage determinants and further extends the concept to voters' mental processing. Many election campaigns use social network sites as a channel of communication strategies. However, such strategies may not influence voters if social network site usage determinants are not considered. Thus, election candidates or campaign managers who aim to develop social media strategies should consider their target audiences' need to belong, perceived ease of use, and perceived usefulness.

Third, election candidates or campaign managers must realise that voters' attitude and confidence cannot be affected simply by accessing social media. By contrast, they should pay more attention on increasing their target audiences' involvement with politics. Our findings indicate that the relationship between social network site usage determinants and voters' attitude and confidence is mediated through voters' involvement with politics (Fig. 2).

Despite its contributions, this study has some limitations. First, the relationship between social media and voters was investigated by considering only the Facebook users of voting age in Taiwan. Although Facebook exhibits the highest penetration among Taiwan social media users, the results may not be considered representative of the entire country because only one network site was used. For future research, respondents from different social network sites or different countries can be recruited to enrich the sample. Second, although the demographic distribution of sampled population in this research is similar to the overall demographic characteristics of Facebook users in Taiwan, potential bias may exist because our respondents were voluntarily participating in the research. For future research, randomly choose the respondents to participate in the survey would decrease the bias. Third, we cannot deny the possibility of other factors that can potentially affect voters' attitude and confidence through social network sites. Therefore, in future studies, the scope of this research can be extended by exploring the moderating effects of voters' personality, information content, and other related factors.

\section{Conclusion}

Social network sites have become one of the important channels for election campaigns. The influence of social network sites on political participation has received considerable attention from academic researchers and business managers. However, there has not been much attention given to the influence of the determinants of social network site usage on voters' involvement, attitude, and confidence. Thus, this research extends the concept of previous research and examines the relationships between social network site usage determinants, voters' involvement with politics, voters' attitude towards voting, and voters' confidence of their decisions. The findings of this research show that the determinants of social network site usage in terms of need to belong, perceived ease of use, and perceived usefulness have positive impact on voters' involvement with politics, which further affects voters' attitude toward voting and their confidence of decisions. These findings contribute to the research on social media and political participation and open many avenues for further explorations. Furthermore, these findings give marketing managers, political workers, and candidates a better understanding of the influence of social network sites on the elections.

\section{Data availability}

The datasets generated and analysed during this study are available in the Dataverse repository, https://doi.org/10.7910/DVN/ 4TNDUP.

Received: 13 August 2019; Accepted: 13 November 2019; Published online: 07 January 2020 


\section{References}

Adams DA, Nelson RR, Todd PA (1992) Perceived usefulness, ease of use, and usage of information technology: a replication. MIS Quart 23:227-247

Ajzen I, Fishbein M (1977) Attitude-behavior relations: a theoretical analysis and review of empirical research. Psychol Bull 84(5):888

Armstrong JS, Overton TS (1977) Estimating nonresponse bias in mail surveys. J Market Res 14:396-402

Barki H, Hartwick J (1994) Measuring user participation, user involvement, and user attitude. MIS Quart 18:59-82

Baron RM, Kenny DA (1986) The moderator-mediator variable distinction in social psychological research: Conceptual, strategic, and statistical considerations. J Personal Soc Psychol 51(6):1173

Baumeister RF, Leary MR (1995) The need to belong: desire for interpersonal attachments as a fundamental human motivation. Psychol Bull 117(3):497

Chadwick A (2006) Internet politics: states, citizens and new communication technologies. Oxford University Press, Oxford

Chang HH, Chuang SS (2011) Social capital and individual motivations on knowledge sharing: participant involvement as a moderator. Inform Manag 48(1):9-18

Davis A (2010) New media and fat democracy: the paradox of online participation1. New Media Soc 12(5):745-761

Dickinson T (2008) March 20. The Machinery of Hope: Inside the grass-roots field operation of Barack Obama, who is transforming the way political campaigns are run. Rolling Stone

Enli G (2017) Twitter as arena for the authentic outsider: exploring the social media campaigns of Trump and Clinton in the 2016 US presidential election. Eur J Commun 32(1):50-61

Facebook (2019) Facebook audience insights. In Facebook Business. https://www. facebook.com/business/insights/tools/audience-insights

Flanagin AJ, Metzger MJ (2001) Internet use in the contemporary media environment. Hum Commun Res 27(1):153-181

Gefen D, Straub DW (1997) Gender differences in the perception and use of e-mail: an extension to the technology acceptance model. MIS Quart 21(4):389-400

Gulati GJ (2004) Members of Congress and presentation of self on the World Wide Web. Harvard Int J Press/Polit 9(1):22-40

Hair JF, Black WC, Babin BJ, Anderson RE, Tatham RL (1998) Multivariate data analysis. Prentice hall, Upper Saddle River p 207-219, Vol. 5, No. 3

Hartwick J, Barki H (1994) Explaining the role of user participation in information system use. Manag Sci 40(4):440-465

Jackson CM, Chow S, Leitch RA (1997) Toward an understanding of the behavioral intention to use an information system. Decision Sci 28(2):357-389

Kwon O, Wen Y (2010) An empirical study of the factors affecting social network service use. Comput Human Behav 26(2):254-263

Lindberg IS, Lührmann A, Gastaldi L, Grahn S, Maxwell L, Mechkova V, Morgan R, Stepanova N, Pillai S (2019) V-Dem Annual Democracy Report 2019. Democracy Facing Global Challenges. V-Dem Institute, University of Gothenburg

Muehling DD, Laczniak RN, Andrews JC (1993) Defining, operationalizing, and using involvement in advertising research: a review. J Curr Issues Res Advert 15(1):21-57

O'Cass A (2002) Political advertising believability and information source value during elections. J Advert 31(1):63-74

O’Cass A, Fenech T (2003) Web retailing adoption: exploring the nature of internet users Web retailing behaviour. J Retail Consumer Services 10(2):81-94

O'Cass A, Pecotich A (2005) The dynamics of voter behavior and influence processes in electoral markets: a consumer behavior perspective. J Business Res 58(4):406-413

Ott BL (2017) The age of Twitter: Donald J. Trump and the politics of debasement. Critical Stud Media Commun 34(1):59-68
Persily N (2017) The 2016 US Election: can democracy survive the internet? J Democracy 28(2):63-76

Pinkleton BE (1998) Effects of Print Comparative Political Advertising on Political Decision-Making and Participation. J Commun 48(4):24-36

Pinkleton BE, Um NH, Austin EW (2002) An exploration of the effects of negative political advertising on political decision making. J Advert 31(1):13-25

Seidman G (2013) Self-presentation and belonging on Facebook: how personality influences social media use and motivations. Personal Individual Differ 54 (3):402-407

Statista (2019) Penetration of leading social networks in Taiwan as of 3rd quarter 2018. In Statista-The Statistics Portal. https://www.statista.com/statistics/ 295611/taiwan-social-network-penetration

Tsai WHS, Men LR (2017) Consumer engagement with brands on social network sites: a cross-cultural comparison of China and the USA. J Market Commun 23(1):2-21

Ward K (2018) Social networks, the 2016 US presidential election, and Kantian ethics: applying the categorical imperative to Cambridge Analytica's behavioral microtargeting. J Media Ethics 33(3):133-148

Williams RL, Cothrel J (2000) Four smart ways to run online communities. MIT Sloan Manag Rev 41(4):81

Zechman MJ (1979) Dynamic models of the voter's decision calculus: incorporating retrospective considerations into rational-choice models of individual voting behavior. Public Choice 34(3-4):297-315

\section{Competing interests}

The author declares no competing interests.

\section{Additional information}

Supplementary information is available for this paper at https://doi.org/10.1057/s41599 019-0368-9.

Correspondence and requests for materials should be addressed to H.L.

Reprints and permission information is available at http://www.nature.com/reprints

Publisher's note Springer Nature remains neutral with regard to jurisdictional claims in published maps and institutional affiliations.

Open Access This article is licensed under a Creative Common Attribution 4.0 International License, which permits use, sharing, adaptation, distribution and reproduction in any medium or format, as long as you give appropriate credit to the original author(s) and the source, provide a link to the Creative Commons license, and indicate if changes were made. The images or other third party material in this article are included in the article's Creative Commons license, unless indicated otherwise in a credit line to the material. If material is not included in the article's Creative Commons license and your intended use is not permitted by statutory regulation or exceeds the permitted use, you will need to obtain permission directly from the copyright holder. To view a copy of this license, visit http://creativecommons.org/ licenses/by/4.0/

(C) The Author(s) 2020 